\title{
Effects of Lead on the Secretion and Disappearance of Renin in Rabbits ${ }^{1}$
}

\author{
JoAn A. KeISER, ${ }^{2}$ ARThur J. VANDER, ${ }^{3}$ AND CARol L. Germain \\ Department of Physiology. The University of Michigan Medical School, Ann Arbor. Michigan 48109
}

Received January 31, 1983; accepted February 17, 1983

\begin{abstract}
Effects of Lead on the Secretion and Disappearance of Renin in Rabbits. KEISER, J. A., Vander, A. J., And Germain, C. L. (1983). Toxicol. Appl. Pharmacol. 69, 117-126. The disappearance rate of renin from plasma was evaluated in both acutely and chronically leadexposed rabbits. In addition, the effects of lead $(\mathrm{Pb})$ on in vitro renin secretion were determined with rabbit renal cortical slices. Rabbits acutely exposed to $\mathrm{Pb}(0.3$ to $2.0 \mathrm{mg} / \mathrm{kg}$, iv) demonstrated no increase in plasma renin activity (PRA), but a markedly prolonged disappearance of renin following nephrectomy. Together, these observations suggest that renin secretion must have been inhibited; consistent with this hypothesis was the finding that rabbit renal cortical slices exposed to $\mathrm{Pb}\left(10^{-5}\right.$ or $\left.10^{-6} \mathrm{M}\right)$ in vitro secreted significantly less renin than did controls. Thus, the effects of large acute doses of $\mathrm{Pb}$ in the rabbit are simultaneous inhibition of both renin secretion and clearance. Chronically $\mathrm{Pb}$-exposed rabbits (500 or $1000 \mathrm{ppm}$ in drinking water) had renin halflives that were not different from controls (6 to $8 \mathrm{~min}$ ). PRA was also not significantly different in the three groups. Renal slices from both groups of Pb-exposed rabbits secreted significantly more renin in vitro compared to controls, despite the fact that renal renin concentrations were similar in the three groups. However, the responsiveness to a beta adrenergic stimulus was significantly lower in the slices from rabbits treated with $1000 \mathrm{ppm} \mathrm{Pb}$. Taken together these data suggest that PR $\Lambda$ in the chronically Pb-exposed rabbit reflects a tendency for increased basal renin secretion, but a counteracting suppression of renin release secondary to adrenergically mediated stimuli; thus, PRA might be reduced, unchanged, or elevated depending upon experimental conditions. Clearance of renin does not seem to be altered in the chronically $\mathrm{Pb}$-cxposcd rabbit.
\end{abstract}

Studies of the renin-angiotensin system in dogs after acute (iv) lead $(\mathrm{Pb})$ exposure have demonstrated profound elevations in plasma renin activity (PRA) associated with a decreased hepatic removal of renin and no consistent changes in renin secretion (Goldman et al., 1981). Significant elevations in PRA have also been reported in rats following both acute and chronic $\mathrm{Pb}$ exposure (Fleischer et

\footnotetext{
${ }^{1}$ This work was supported by NIOSH Grant $5 \mathrm{R} 01 \mathrm{OH}$ 00913.

2 This work was done in partial fulfillment of requirements for the PhD degree by J. A. Keiser. Current address: Department of Physiology and Biophysics, Mayo School of Medicine, Rochester, Minn. 55905

${ }^{3}$ To whom reprint requests should be addressed.
}

al., 1980; Mouw et al., 1978; Victery et al., 1982a). These observations have led to the hypothesis that the abnormal PRA found in the chronically $\mathrm{Pb}$-exposed animal might be the result of a defect in the removal of renin rather than a change in renin secretion (Goldman et al., 1981).

The present experiments were performed to evaluate this hypothesis by determining the effects of chronic lead exposure on the disappearance of endogenous renin following nephrectomy and on the secretion of renin from renal cortical slices in vitro. The rabbit, rather than rat or dog, was selected as the experimental animal because of its convenient size. The effects of $\mathrm{Pb}$ on the rabbit's 
renin-angiotensin system have not previously been examined; therefore, we first determined whether acute exposure to $\mathrm{Pb}$ inhibited renin clearance in a manner similar to that described for dog (Goldman et al., 1981).

\section{METHODS}

All experiments were performed on male New Zealand white rabbits (Oryctolagus cuniculus), Spartan Labs, Lansing, Mich.) weighing 2.0 to $2.5 \mathrm{~kg}$. Animals were housed in individual wire-floored cages in temperature-controlled rooms $\left(24^{\circ} \mathrm{C}\right)$ on a fixed light schedule $(0600-1800)$. Food (Teklad rabbit chow; Madison, Wisc.) and water were available ad libitum. Rabbits used for acute experiments were kept at least 1 week prior to use. Chronic animals were kept for 1 week before being allocated to specific treatment groups.

\section{Protocol 1. Effects of Acute Pb Exposure on the Disap pearance of Renin}

Three days prior to the renin-disappearance experiments each rabbit was anesthetized with a combination of xylazine (Rompun, Cutter Laboratories; $10 \mathrm{mg} / \mathrm{kg}, \mathrm{im}$ ) and ketamine hydrochloride (Vetalar, Parke Davis; 35 $\mathrm{mg} / \mathrm{kg}$, im). A midline incision $(5$ to $6 \mathrm{~cm}$ ) was made on the ventral aspect of the neck, and the left external jugular vein was exposed and cannulated. The cannula was passed sc into the ear lobe and exteriorized. On the day of the experiment an unanesthetized rabbit was placed in a restrainer and given an infusion of $\mathrm{Pb}$ acetate $(0.3$ to 2.0 $\mathrm{mg} / \mathrm{kg}$ : $\mathrm{Pb}$ treated) or an equimolar solution of sodium acetate (TC; time-control) via the jugular catheter. Solutions were made by dissolving either $\mathrm{Pb}$ or sodium acetate in sterile saline; the total volume infused was 2.0 $\mathrm{ml} / \mathrm{kg}$, and was given over approximately $50 \mathrm{~min}$ with a Harvard infusion pump. Two hours after completion of the infusion the rabbit was again anesthetized with $x y-$ lazine and ketamine. An abdominal midline incision was made, and a catheter (PE-160) was inserted into the abdominal aorta proximal to its bifurcation. The right and left kidneys were isolated and cleared of connective tissue; loose ligatures were placed around the renal artery and vein on cach side. A single blood sample $(0.5 \mathrm{ml})$ was drawn from the aortic catheter and replaced with an equal volume of saline. Four to five minutes later the vessels to both kidneys were firmly tied and the kidneys removed from the abdomen. A simultaneous blood sample $(0.5$ $\mathrm{ml}$ ), designated the zero sample, was withdrawn; additional samples were drawn at $2,4,6,8,10,15,20,30$, 40 , and 50 min postnephrectomy. At completion of the protocol the animal was killed with an iv injection of sodium pentobarbital $(120 \mathrm{mg} / \mathrm{kg})$.
All blood samples were collected in tubes containing $0.05 \mathrm{ml}$ of disodium cthylencdiaminetetraacetatc $(0.2 \mathrm{M})$; samples for measurement of angiotensin converting enzyme (ACE) activity were collected in heparin $(1000 \mu$ ) $\mathrm{ml})$. Samples were chilled, centrifuged, and separated at $4^{\circ} \mathrm{C}$, and the plasma was frozen for subsequent analysis.

\section{Protocol 2: Effects of Chronic Pb Exposure on the Dis- appearance of Renin}

Rabbits were randomly allocated to treatment groups of $0(n=5), 500(n=7)$, or $1000(n=5) \mathrm{ppm} \mathrm{Pb}$ (as $\mathrm{Pb}$ acetate) added to the drinking water. No attempt was made to determine any other $\mathrm{Pb}$ burden imposed by the air, food, or water available to the animals. During the seventh week of $\mathrm{Ph}$ treatment, rabbits were subjected to the same renin-disappearance experiments previously described (Protocol 1), except that the experiments were not preceded by acute $\mathrm{Pb}$ infusions.

\section{Protocol 3: Effects of Chronic Pb Exposure on the Secre- tion of Renin in Vitro}

In this series of experiments cortical slices were made from the kidneys of the rabbits described in Protocol 2 above. After nephrectomy the left kidney was placed in a beaker of ice-cold isotonic saline. The renal artery was cannulated and the kidney flushed with cold saline until the venous effluent became clear. Renal cortical slices (0.5-mm thick) were cut by hand with a Stadie-Riggs slicing apparatus. Slices were cut perpendicular to the surface of the kidney. The cortical slices were preincubated in a common flask containing $150 \mathrm{ml}$ of a KrebsRinger bicarbonate buffer ( $124 \mathrm{mM} \mathrm{NaCl}, 5 \mathrm{mM} \mathrm{KCl} .19$ $\mathrm{mM} \mathrm{NaHCO}, 2.6 \mathrm{mM} \mathrm{CaCl}_{2}, 1.2 \mathrm{mM} \mathrm{NaH} \mathrm{NO}_{4}$, and $0.2 \mathrm{~g} / \mathrm{dl}$ glucose) aerated with $95 \% \mathrm{O}_{2}$ and $5 \% \mathrm{CO}_{2}$ at $38^{\circ} \mathrm{C}$ for $45 \mathrm{~min}$. The medium was replaced 15 and 30 min into the preincubation with fresh prewarmed solution.

At the end of the preincubation, slices were randomly allocated to one of three treatment groups; $5 \mathrm{mM} \mathrm{K} \mathrm{K}^{+}, 35$ $\mathrm{mM} \mathrm{K}$, or $35 \mathrm{mM} \mathrm{K}{ }^{+}$with $10^{-6} \mathrm{M}$ isoproterenol. Individual flasks containing $7.5 \mathrm{ml}$ of buffer were incubated in a Dubnoff metabolic shaker bath at $38^{\circ} \mathrm{C}$. A small aliquot $(0.05 \mathrm{ml})$ of concentrated $\mathrm{KCl}$ was added to the flasks of the last two groups to achieve a final concentration of $35 \mathrm{~mm} \mathrm{~K}^{+}$; in addition, the flasks of the final group received $0.075 \mathrm{ml}$ of $10^{-4} \mathrm{M}$ isoproterenol to achieve the final concentration of $10^{-6} \mathrm{M}$. Medium samples were collected into chilled tubes at $150 \mathrm{~min}$. The samples were immediately centrifuged at $4^{\circ} \mathrm{C}$ to remove small tissue debris, and the supernatant fraction was stored at $-30^{\circ} \mathrm{C}$ for later analysis of its renin concentration. At the end of the incubation period the slices were quickly removed, blotted, and placed in tared chilled tubes containing 0.5 
$\mathrm{ml}$ of saline. The tubes were reweighed and stored at $-30^{\circ} \mathrm{C}$.

Protocol 4: Effects of in Vitro Pb Exposure on Renin Secretion by Cortical Slices

In this series of experiments renal cortical slices were exposed to $\mathrm{Pb}$ in vitro during the incubation period. Kidneys were obtained from rabbits which had undergone no previous treatment. Slices were prepared as described in Protocol 3. Slices were preincubated and incubated in a solution having the same composition as that of protocol 3, except the $\mathrm{KCl}$ concentration was $25 \mathrm{~mm}$ (this value was used to provide somewhat higher renin-secretion values than seen at $35 \mathrm{~mm}$ so that it would be possible to see any potential $\mathrm{Pb}$-induced inhibition of secretion). Following the preincubation, slices were randomly allocated to one of three treatment groups; control, $10^{-5} \mathrm{M}$ $\mathrm{Pb}$, or $10^{-6} \mathrm{M} \mathrm{Pb}$. A $10^{-3} \mathrm{M} \mathrm{Pb}$ acetate stock solution was made in deionized distilled water, and the $\mathrm{pH}$ was adjusted to 5.5 to prevent precipitation. Aliquots $(0.075 \mathrm{ml})$ of this stock or of a 10 -fold dilution were added to incubation flasks of the lead-treated groups to achieve final concentrations of $10^{-5}$ and $10^{-6} \mathrm{M} \mathrm{Pb}$, respectively. Medium samples were collected after $60,90,120$, and 150 min of incubation and handled as described in Protocol 3 .

\section{Analytical Methods}

Hematocrit was measured on a microhematocrit reader after centrifugation in a microcapillary centrifuge for 5 min. Plasma sodium and potassium concentrations were determined by flame photometry. Blood lead was measured by graphite furnace atomic absorption (Varian Instruments, Model 375 CRA 90) by methods of addition. $A C E$ activity was measured in plasma and lung tissue from chronic animals only. A commercially available kit for plasma ACE microdeterminations was obtained from Ventrex Corporation. The supernatant fraction of homogenized lung tissue was spectrophotometrically assayed for ACE activity by the method of Wallace $e t$ al. (1978) with the major modification that the phosphate buffer was replaced with a Tris buffer. This assay measures the rate of generation of hippuric acid from hippuryl-Lhistidyl-L-leucine by lung homogenates. Protein in the pulmonary supernatant fraction was assayed by the method of Lowry et al. (1951).

Methods for the measurement of PRA, plasma renin substrate (angiotensinogen, PRS), and renal renin concentration (RRC) have been described previously (Mouw et al., 1978); the maleate buffer used in assaying rabbit samples was pH 6.5. Cortical slice media were assayed for renin activity after the addition of substrate to the incubation mixture. The renin substrate used was plasma from rabbits nephrectomized 48 hr previously; the substrate concentration of the final incubation solution was equivalent to $800 \mathrm{ng}$ angiotensin $\mathrm{l} / \mathrm{ml}$. Maleate buffer ( 50

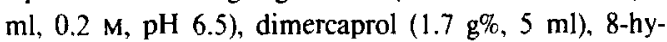
droxyquinolone $(6.6 \mathrm{~g} \%, 5 \mathrm{ml})$, and EDTA $(0.2 \mathrm{M}, 2 \mathrm{ml})$ were added to $100 \mathrm{ml}$ of the substrate. Aliquots $(0.162$ $\mathrm{ml})$ of this solution were pipetted into individual tubes and stored at $-30^{\circ} \mathrm{C}$ for later use. Medium samples $(0.05$ $\mathrm{ml}$ ) were added to these substrate tubes and incubated as previously described for the renin assay (Mouw et al. 1978).

\section{Statistical Analysis}

Data were analyzed with analysis of variance (ANOVA) by a one-way classification (Steel and Torrie, 1960). Differences between treatment groups within the ANOVA were determined with Duncan's New Multiple Range test (DNMR) (Steel and Torrie, 1960). A p value less than 0.05 was accepted as significant. All group values are given as means $\pm 1 \mathrm{SE}$.

\section{RESULTS}

\section{Protocol 1: Effects of Acute Pb Exposure on the Disappearance of Renin}

Zero-time values for PRA were $10.4 \pm 3.9$ $\mathrm{ng} \mathrm{AI} / \mathrm{ml} / \mathrm{hr}$ in the $\mathrm{TC}$ rabbits; the mean value in $\mathrm{Pb}$-treated rabbits was $5.6 \pm 0.7$. Figure 1 depicts mean curves for the fall in PRA (expressed as a percentage of the PRA at time zero) in the acutely $\mathrm{Pb}$-exposed and $\mathrm{TC}$ rabbits; data are plotted on semilog scale. It is apparent that although PRA fell in both groups during the first $10 \mathrm{~min}$, the slope of the line for the TC group was much steeper. The mean half-life in the controls was $8.2 \pm 2.4 \mathrm{~min}$. In four of the five $\mathrm{Pb}$-treated rabbits, PRA never reached $50 \%$ of its initial value during the 50 min sampling period. The single exception had a half-life of $4 \mathrm{~min}$, a value similar to those observed in the TC rabbits. No statistical comparison of half-lives for the two groups could be made since four of the five $\mathrm{Pb}$ rabbits never reached this endpoint. PRS was measured in two animals from each group at 10,30 , and 50 min postnephrectomy; values were similar in all four animals and did not fall in any of the rabbits during the course of the experiment. 


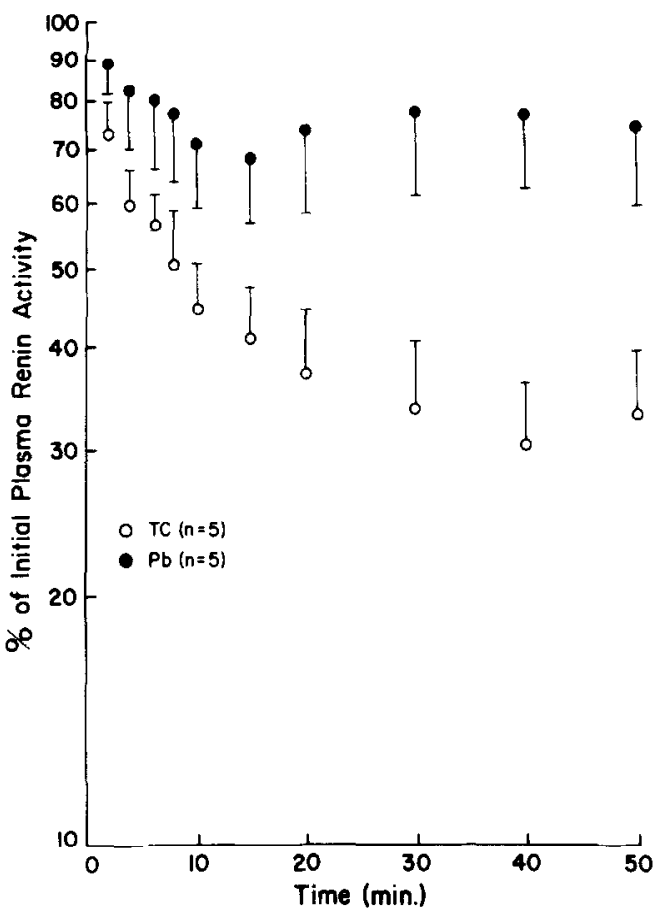

F1G. 1. Postnephrectomy fall in plasma renin activity (PRA) in rabbits acutely given sodium acetate (time-controls, $\mathrm{TC})$ or $\mathrm{Pb}$ acetate $(\mathrm{Pb})$ iv. See text for description of $\mathrm{Pb}$ exposure.

Protocol 2. Effects of Chronic Pb Exposure on the Disappearance of Renin

Zero time values for PRA were not different between the three groups: $\mathrm{TC}=13.0$ $\pm 5.0 \mathrm{ng} \mathrm{AI} / \mathrm{ml} / \mathrm{hr}, 500 \mathrm{ppm}=14 \pm 7.1,1000$ $\mathrm{ppm}=18.2 \pm 5.2$. There were no significant differences in the half-life of renin in the three groups of chronic rabbits. The postnephrectomy fall in PRA (normalized to percentage of the initial value) in the three groups is depicted in Fig. 2. All three groups showed a rapid drop within the first $15 \mathrm{~min}$ and a slower fall during the remainder of the experiment. The mean half-lives for renin in the three groups are depicted in Fig. 3: $\mathrm{TC}=8.2 \pm 2.4$ $\min , 500 \mathrm{ppm}=7.0 \pm 1.2$, and $1000 \mathrm{ppm}=$ $6.4 \pm 2.2$.

Blood $\mathrm{Pb}$ concentrations were elevated in the 500 and 1000 ppm groups to $66 \pm 10$ and $109 \pm 15 \mu \mathrm{g} / \mathrm{dl}$, respectively (Table 1). Body weights and kidney weights, plasma $[\mathrm{Na}]$ and
[K], and both lung and plasma ACE activities were similar in the three groups. Hematocrit was depressed by approximately $10 \%$ in the 1000-ppm rabbits compared to the other two groups, consistent with a modest $\mathrm{Pb}$-induced anemia. Mean arterial blood pressures at the time of nephrectomy were $71 \pm 4$ (TC), 71 $\pm 5(500 \mathrm{ppm})$, and $67 \pm 8(1000 \mathrm{ppm})$; these differences were not statistically significant.

\section{Protocol 3: Effects of Chronic Pb Exposure on the in Vitro Secretion of Renin}

Previously performed pilot studies had demonstrated that renin secretion from cortical slices was linear from 90 to $150 \mathrm{~min}$ of incubation and so, for ease of analysis, only the 150-min samples were used. These pilot experiments also confirmed the findings by others (Churchill and Churchill, 1979, 1980) that elevation of potassium concentration in the medium reduced renin secretion from the

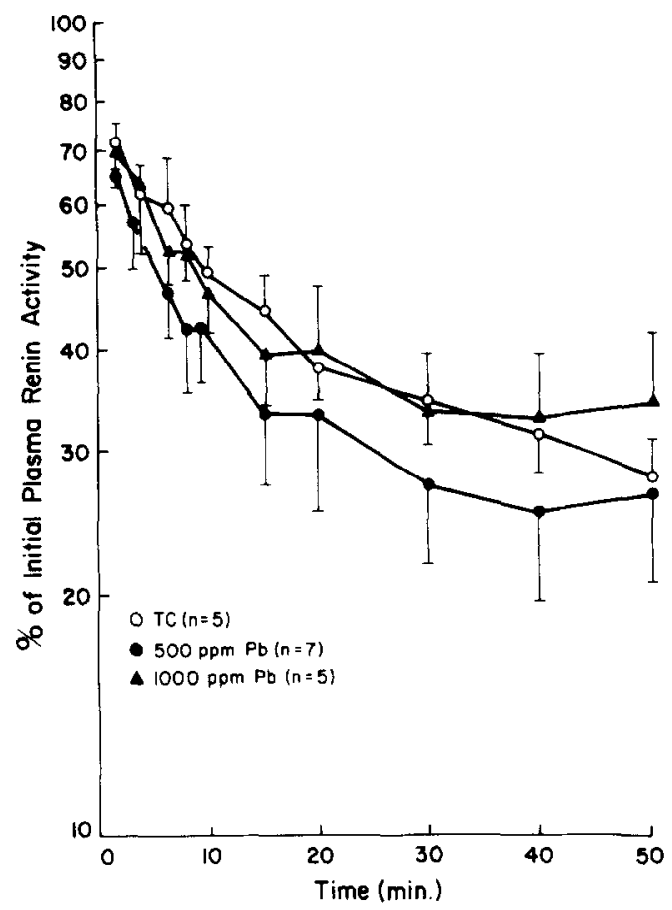

FIG. 2. Effects of chronic Pb-exposure on the postnephrectomy fall in plasma renin activity (PRA) in rabbits. See text for description of treatment. 


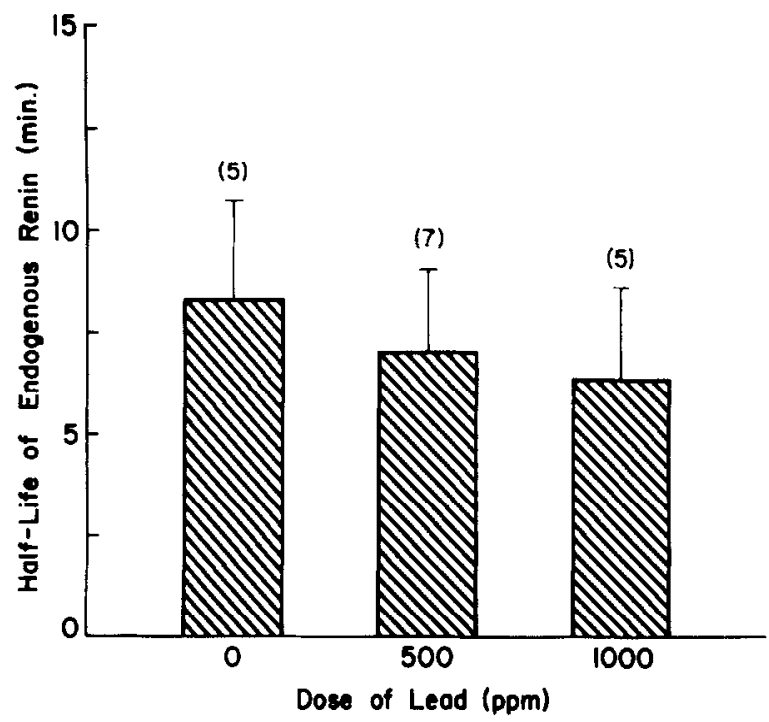

FIG. 3. The mean half-life of endogenous renin in the three groups of chronic rabbits depicted in Fig. 2.

slices to values similar to those occurring in vivo. Therefore, for evaluation of "basal" renin secretion by the slices, we chose a potassium concentration ( $35 \mathrm{mM}$ ) which reduced renin secretion to approximately $33 \%$ of the value observed with $5 \mathrm{mM} \mathrm{K}$. Accordingly, two different methods for stimulating renin secretion above "basal" were then used: isopro- terenol and medium $\mathrm{K}^{+}$concentration of $5 \mathrm{~mm}$.

Table 2 presents data on the secretion of renin in vitro from the three groups of chronically Pb-exposed rabbits used in Protocol 2. Basal renin secretion $\left(35 \mathrm{mM} \mathrm{K} \mathrm{K}^{+}\right.$) was approximately twofold higher in the flasks containing slices from chronically $\mathrm{Pb}$-treated rab-

TABLE 1

Blood lead Concentrations, Organ Weights, and Other Parameters in lead-Exposed Rabbits

\begin{tabular}{|c|c|c|c|}
\hline \multirow[b]{2}{*}{ Indices } & \multicolumn{3}{|c|}{ Dose of lead ${ }^{a}$ added to drinking water } \\
\hline & $\begin{array}{c}0 \mathrm{ppm} \\
\text { (control, } n=5)\end{array}$ & $\begin{array}{c}500 \text { ppm } \\
(n=7)\end{array}$ & $\begin{array}{c}1000 \mathrm{ppm} \\
(n=5)\end{array}$ \\
\hline Blood $[\mathrm{Pb}](\mu \mathrm{g} / \mathrm{dl})$ & $7 \pm 3$ & $66 \pm 10$ & $109 \pm 15$ \\
\hline Body weight (kg) & $3.24 \pm 0.12$ & $3.42 \pm 0.13$ & $3.31 \pm 0.13$ \\
\hline Kidney weight $(\mathrm{g})$ & $8.67 \pm 0.22$ & $8.43 \pm 0.50$ & $8.70 \pm 0.44$ \\
\hline IIematocrit $(\times 100)$ & $38.9 \pm 1.4$ & $38.2 \pm 1.4$ & $34.2 \pm 2.1$ \\
\hline Plasma $[\mathrm{Na}](\mathrm{mM})$ & $140.5 \pm 3.0$ & $141.2 \pm 1.3$ & $141.2 \pm 2.3$ \\
\hline Plasma $[\mathrm{K}](\mathrm{mM})$ & $3.89 \pm 0.23$ & $4.25 \pm 0.22$ & $4.33 \pm 0.21$ \\
\hline $\begin{array}{l}\text { Lung converting enzymc activity } \\
\text { ( } \mathrm{mmol} / \mathrm{min} / \mathrm{mg} \text { protein) } \\
\text { Plasma converting enzyme activity }\end{array}$ & $31.8 \pm 1.8$ & $29.3 \pm 1.5$ & $30.9 \pm 1.6$ \\
\hline (nmol $/ \mathrm{min} / \mathrm{ml}$ plasma) & $503.5 \pm 20.0$ & $474.9 \pm 17.6$ & $476.3 \pm 61.2$ \\
\hline
\end{tabular}

Note. Data are group means $\pm 1 \mathrm{SE}$.

${ }^{a}$ As lead acetate. 
TABLE 2

IN VITRo RENIN SECRETION DURING 150-min INCUBatION WITH SLICES FROM Chronically Lead-Exposed RabBits

\begin{tabular}{|c|c|c|c|}
\hline \multirow[b]{2}{*}{$\begin{array}{c}\text { Renin secreted } \\
\text { (ng angiotensin I/mg kidney) }\end{array}$} & \multicolumn{3}{|c|}{ Dose of lead ${ }^{a}$ added to drinking water } \\
\hline & $\begin{array}{c}0 \mathrm{ppm} \\
\text { (control, } n=6 \text { ) }\end{array}$ & $\begin{array}{c}500 \mathrm{ppm} \\
(n=6)\end{array}$ & $\begin{array}{c}1000 \mathrm{ppm} \\
(n=6)\end{array}$ \\
\hline A. $35 \mathrm{~mm} \mathrm{~K}^{+}$ & $0.84 \pm 0.19$ & $1.61 \pm 0.31^{b}$ & $1.63 \pm 0.30^{b}$ \\
\hline B. $35 \mathrm{mM} \mathrm{K}^{+}$with $10^{-6} \mathrm{M}$ Isoproterenol & $1.63 \pm 0.30$ & $2.78 \pm 0.35^{b}$ & $2.01 \pm 0.29$ \\
\hline C. $5 \mathrm{mM} \mathrm{K}^{+}$ & $2.34 \pm 0.50$ & $3.63 \pm 0.34$ & $3.97 \pm 0.72$ \\
\hline \multicolumn{4}{|l|}{ Ratio } \\
\hline $\mathrm{B} / \mathrm{A}$ & $2.09 \pm 0.31$ & $1.87 \pm 0.20$ & $1.32 \pm 0.20$ \\
\hline $\mathrm{C} / \mathrm{A}$ & $3.32 \pm 0.94$ & $2.59 \pm 0.46$ & $2.60 \pm 0.45$ \\
\hline
\end{tabular}

Note. Data are group means \pm 1 SE.

a As lead acetate.

${ }^{b}$ Significantly different from control, $p<0.05$.

bits compared to time controls $(p<.05$ for both $\mathrm{Pb}$-treated groups). Stimulation of renin secretion with isoproterenol $\left(10^{-6} \mathrm{M}\right)$ increased the renin secretion in all three treatment groups above that in $35 \mathrm{mM} \mathrm{K}^{+}$alone. The absolute value for sccrction in $35 \mathrm{mM} \mathrm{K}^{+}$ with isoproterenol was greatest in the $500 \mathrm{ppm}$ group and was significantly different from the other two groups $(p<.05)$; the value for the 1000 -ppm group did not differ significantly from control. Stimulation of renin secretion with $5 \mathrm{mM} \mathrm{K}^{+}$increased renin secretion approximately threefold in all three groups; there were no significant differences between the absolute values for the three groups.

To isolate the effects of isoproterenol and those of low $\mathrm{K}^{+}$from those of high $\mathrm{K}^{+}$(i.e., to take into account the fact that basal secretion rates were different in the three groups), the data for these two other media were evaluated as the ratios to secretion rates in $35 \mathrm{~mm}$ $\mathrm{K}^{+}$and are presented in Table 2 . The percentage stimulation by isoproterenol was significantly less in the 1000-ppm group then in the control group.

Despite the elevated basal renin secretion exhibited by the $\mathrm{Pb}$-treated groups, renal renin concentrations in the three groups of rabbits were similar: $\mathrm{TC}=331 \pm 47 \mathrm{ng} \mathrm{AI} / \mathrm{mg} \mathrm{kid}$ - ney, $500 \mathrm{ppm}=308 \pm 37$, and $1000 \mathrm{ppm}$ $=382 \pm 49$.

Protocol 4: Effects of in Vitro Pb Exposure on Renin Secretion by Cortical Slices

Renin secretion rates in the presence of 0 , $10^{-5}$, and $10^{-6} \mathrm{M} \mathrm{Pb}$ (added to the incubation media) are shown in Fig. 4. These cortical slices were prepared from rabbits that had not undergone previous $\mathrm{Pb}$ treatment. At each sampling the mean absolute values of secreted renin were lower for the $\mathrm{Pb}$-exposed slices than for controls, but these differences were not significant. However, since basal secretion varied widely from animal to animal, we normalized data between animals, i.e., compared the values for $\mathrm{Pb}$-cxposed slices to those for the same animals' control slices. Slices incubated in $10^{-5} \mathrm{M} \mathrm{Pb}$ secreted renin at $89 \pm 11$, $86 \pm 9,86 \pm 10$, and $79 \pm 4 \%$ of the values for control flasks at $60,90,120$, and $150 \mathrm{~min}$, respectively. Mean secretion from slices incubated in $10^{-6} \mathrm{M} \mathrm{Pb}$ was $72 \pm 19,82 \pm 9$, $83 \pm 12$, and $89 \pm 12 \%$ during these same intervals. Because the two groups had similar responses, the data were pooled for analysis. The percentage inhibition of $10^{-5}$ or $10^{-6} \mathrm{M}$ 


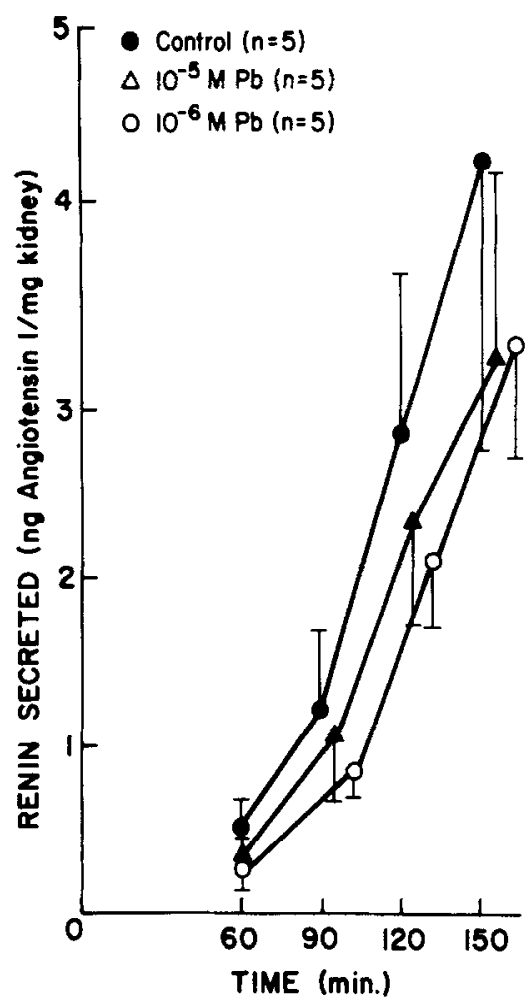

FIG. 4. Renin secretion from kidney cortical slices exposed to $\mathrm{Pb}$ (as $\mathrm{Pb}$ acetate) in vitro during 150-min incubation.

lead compared to normalized control secretion at 150 min was significantly different ( $p$ $<.05$ ) by a paired $t$ statistic.

\section{DISCUSSION}

These experiments demonstrate that the disappearance of renin from plasma following nephrectomy in acutely $\mathrm{Pb}$-exposed rabbits is markedly inhibited, whereas chronically $\mathrm{Pb}$ exposed rabbits are unaffected. Quantitation of the data depends upon the manner in which the disappearance curves are evaluated. The disappearance curves for renin clearly do not fit a single exponential. There is a rapid fall in PRA during the first 10 to $15 \mathrm{~min}$ postnephrectomy followed by a much slower decline, a pattern previously reported by other investigators (Michelakis and Mizukoshi, 1971; Schaechtelin et al., 1964; Schneider et al., 1968). ${ }^{4}$ There is disagreement concerning the mechanisms contributing to this shape of the disappearance curve. Schneider and colleages (1968) have suggested that the initial rapid fall in renin is due to a redistribution of renin into a second compartment (for example, the extravascular space) rather than to actual elimination by the liver, and that the slower component of the renin disappearance curve actually reflects the true clearance of renin. Using this criterion, Schneider estimated a renin half-life of $45 \mathrm{~min}$ in the anesthetized dog (Schneider et al., 1968). Using a similar approach to the data, Michelakis and Mizukoshi (1971) predicted a slow-component renin half-life of $93 \pm 17(\mathrm{SD}) \mathrm{min}$ in dogs and $280 \pm 94$ (SD) min in humans.

Implicit in the logic behind the redistribution concept is the assumption that renin secretion must have been stimulated during anesthesia or nephrectomy and that equilibration between plasma and interstitial fluid had not yet been reached at the moment of nephrectomy. In our experiments there was no consistent rise or fall in PRA between the first two samples obtained in the present experiment (pre and zero), which suggests that no large burst of renin secretion had occurred. However, we have no direct proof of equilibration between plasma and interstitial fluid.

If one chooses not to separate the disappearance curves into multiple components, but simply uses the raw data, a much shorter half-life results. For example, Oates (1974) measured an endogenous renin half-life of 10 $\mathrm{min}$ in the anesthetized rat, a value similar to our present value for the rabbit. These lower values are more consistent with directly measured values for hepatic renin extraction in the literature, which average approximately $30 \%$ for all species studies (Goldman et al., 1981; Horky et al., 1970; Mitch et al., 1979;

\footnotetext{
${ }^{4} \mathrm{~A}$ possible problem in the present experiments could be an increase in PRS following nephrectomy, since such an increase would elevate PRA. However, no change in substrate was observed during the 50 min postnephrectomy; therefore, PRA was a valid indicator of plasma renin concentration.
} 
Tapia et al., 1973). Even assuming a total extracellular fluid volume of distribution for renin in the steady state, this extraction ratio coupled with the very high rates of hepatic blood flow leads to calculated half-lives much shorter than 45 to $90 \mathrm{~min}$.

Since the physiological significance of multiple components in the renin disappearance curves is unclear, we chose to estimate a single value for half-life. Renin half-life was approximately $8 \mathrm{~min}$ in acute TC rabbits. In four of the five acutely $\mathrm{Pb}$-exposed animals, the half-life was markedly prolonged (>50 min). This finding is consistent with the report by Goldman et al. (1981) that directly measured hepatic renin extraction was virtually eliminated in dogs following acute $\mathrm{Pb}$ exposure. The renin half-life of the fifth $\mathrm{Pb}$ exposed rabbit in this study was comparable to controls; this rabbit received the lowest dose of $\mathrm{Pb}(0.3 \mathrm{mg} / \mathrm{kg})$, suggestive of a possible threshold effect.

The mean value for PRA tended to be lower at the start of the experiment in the acutely $\mathrm{Pb}$-exposed rabbits $(5.6 \pm 0.7 \mathrm{ng} \mathrm{AI} / \mathrm{ml} / \mathrm{hr})$ compared to TC animals (10.4 \pm 4.0$)$. One would have predicted an elevated PRA if a decrease in the clearance of renin were the only $\mathrm{Pb}$-induced effect. One must postulate, therefore, that renin secretion was also virtually eliminated by acute $\mathrm{Pb}$-exposure. Consistent with this hypothesis was the finding that the acute exposure of renal slices to $\mathrm{Pb}$ in vitro resulted in inhibition of renin secretion. The ability of $\mathrm{Pb}$ to inhibit renin secretion has been previously suggested by data from people (Bertel et al., 1978) and rats whose cxposurc was begun in utero (Victery et al., (1982b)).

In contrast to the acute experiments, there was no difference in the renin disappearance curves in chronically $\mathrm{Pb}$-exposed rabbits, indicating that any observed changes in PRA are not due to altered renin clearance but to altered renin secretion. This hypothesis can be tested directly in the intact animal only by obtaining measurements of renal plasma flow and renin concentrations in arterial and renal venous plasma. This procedure is extremely difficult to achieve in unanesthetized, relatively small experimental animals and so we chose to use renal cortical slices instead, since it is generally accepted that release of renin from slices in vitro parallels renin secretion in vivo (Park et al., 1978). Moreover, measuring renin secretion in vitro also eliminates many of the feedback loops that alter renin secretion in the intact animal, and permits the testing of direct effects of $\mathrm{Pb}$ (added in vitro).

These experiments demonstrate that basal renin secretion by rabbit cortical slices is indeed increased following chronic $\mathrm{Pb}$ exposure. It has been demonstrated that basal renin secretion both in vitro and in vivo is highly correlated with kidney renin stores (Park et al., 1978). The increased secretory rates seen in these experiments would be readily explained if renal renin content were elevated in the $\mathrm{Pb}$-exposed rabbit, as is the case for rats exposed to a similar dietary dose (Fleischer et al., 1980). However, there were no significant differences in renal renin content among the three groups of rabbits. It is possible that the total renin content measured may not reflect the pool from which renin secretion actually occurs, and that $\mathrm{Pb}$ may alter distribution between different pools.

The fact that chronic $\mathrm{Pb}$ exposure stimulated renin secretion from cortical slices is consistent with the hypothesis that $\mathrm{Pb}$ competes with calcium for influx into juxtaglomerular cells. If the two cations vied for entry into the justaglomerular cells, increasing concentrations of $\mathrm{Pb}$ would decrease calcium influx and thereby stimulate renin secretion (Churchill and Churchill, 1980; Fray, 1980; Park and Malvin, 1978). Kapoor and van Rossum (1977) have reported that $2 \times 10^{-4}$ $\mathrm{M} \mathrm{Pb}$ inhibited net movement of calcium into rat kidney slices.

The lesser increment in renin release following a $\beta$-adrenergic stimulus from the chronic $\mathrm{Pb}$-exposed slices is consistent with previous reports on both $\mathrm{Pb}$-exposed rats and people (Bertel et al., 1978; Fleischer et al., 1980), and adds further support to the use of 
slices as an analogue for in vivo renin secretion. A number of investigators have proposed that $\beta$-adrenergic stimuli promote renin secretion by increasing the sequestration or extrusion of calcium from intracellular pools; our results are consistent with this hypothesis since low concentrations of $\mathrm{Pb}$ have been shown to inhibit the calcium-accumulating ability of mitochondria (Parr and Harris, 1976). Although all our results from chronic lead-exposed rabbits can be interpreted in terms of lead interfering with calcium fluxes, many other interpretations are possible. For example, the inhibition of response to isoproterenol could reflect a direct interference with $\beta$ receptors.

The combination of chronically increased basal renin secretion and unchanged renin clearance should lead to increased PRA in the intact animal. The failure to observe such an increase in the samples taken just prior to nephrectomy was a surprising finding, (particularly since an increase in PRA does occur in rat [Fleischer et al., 1980; Victery et al., 1982a]) and could call into question whether the acute disappearance curves and in vitro slice data are adequate indicators of in vivo steady-state processes. However, it must be emphasized that the samples for PRA were taken following anesthesia and surgery, whereas in the previous studies with rats, samples were obtained by decapitation of carefully conditioned animals. Accordingly, there should be a considerable increase in sympathetic activity in the rabbits, acting as a stimulus for renin secretion. The fact that $\mathrm{Pb}$-exposure blunts the renin response to $\beta$-adrengeric stimulation could account for a smaller rise in PRA, i.e., no difference in PRA between time-control and $\mathrm{Pb}$-exposed groups would be expected when renin secretion is under strong sympathetic stimulation.

In summary, responses of the rabbit to acute high-dose and chronic low-dose $\mathrm{Pb}$-exposure are quite different. For the first case, the data indicate inhibition of both the secretion and clearance of renin. For the second case, the data indicate that clearance is unchanged, basal secretion is enhanced, and sympathetically mediated secretion is blunted.

\section{ACKNOWLEDGMENTS}

The authors express their gratitude to Kathleen Schneider for preparation of the manuscript.

\section{REFERENCES}

Bertel, O., Buhler, F. R., AND OtT, J. (1978). Lead induced hypertension: blunted beta-adrenoreceptormediated functions. Brit. Med. J. 1, 551-553.

Churchill, P. C., ANd Churchill, M. C. (1979). Inhibition of in vitro renin secretion by low extracellular K. Life Sci. 25, 687-692.

Churchill, P. C., AND Churchill, M. C. (1980). Biphasic effect of extracellular $\mathrm{K}$ on isoproterenol stimulated renin secretion from rat kidney slices. $J$. Pharmacol. and Exper. Ther. 214, 541-545.

FleisCHER, N., MOUX, D. R., AND V ANDER, A. J. (1980). Chronic effects of lead on renin and renal sodium excretion. J. Lab. Clin. Med. 95, 759-770.

FrAY, J. C. S. (1980). Stimulus-secretion coupling of renin. Circ. Res. 47, 485-492.

Goldman, J. M.. Vander, A. J., Mouw, D. R., Keiser, J., AND NICHOLLS, M. G. (1981). Multiple short-term effects of lead on the renin-angiotensin system. J. Lab. Clin. Med. 97, 251-263.

Horky, K., Rojo-OrTEGA, J. M., Rodriguez, J., AND GENEST, J. (1970). Renin uptake and excretion by liver in the rat. Amer. J. Physiol. 219, 387-390.

KaPOOR, S. C., AND VAN RosSUM, G. D. V. (1977). Effect of lead in vitro on movements of calcium in kidney cortex slices and mitochondria (Abstract). Pharmacologist 19, 180.

Lowry, O. M., Rosebrough, N. J., FARr, A. L., AND RANDALL, R. J. (1951). Protein measurements with the Folin phenol reagent. J. Biol. Chem. 193, 265-275.

Michelakis, A. M., AND Mizukoshi, H. (1971). Distribution and disappearance rate of renin in man and dog. J. Clin. Endo. 33, 27-34.

Mitch, W. E., Whelton, P. K.. COOKe. C. R., Walker. W. G., AND Maddrey, W. C. (1979). Plasma levels and hepatic extraction of renin and aldosterone in alcoholic liver disease. Amer. J. Med. 66, 804-810.

MOUW, D. R., VANDER, A. J., Cox, J., AND Fleischer. N. (1978). Acute effects of lead on renal electrolyte excretion and plasma renin activity. Toxicol. and Appl. Pharmacol. 46, 435-447.

OATES, H. F. (1974). Disappearance rate of circulating renin after bilateral nephrectomy in the rat. Clin. and Exp. Pharmacol and Physiol. 1, 547-549.

Park, C. S., AND Malvin, R. L. (1978). Calcium in the 
control of renin release. Amer. J. Physiol. 235, F22F25.

Park, C. S., Malvin, R. L., Murray, R. D., and Cho, K. W. (1978). Renin secretion as a function of renal renin content in dogs. Amer. J. Physiol. 234, F506F509.

PARR, D. R., AND Harris, E. J. (1976). The effect of lead on the calcium-handling capacity of rat heart mitochondria. Biochem. J. 58, 289-294.

Schaechtelin, G., Regol, D., AND Gross, F. (1964). Quantitative assay and disappearance rate of circulating renin. Amer. J. Physiol. 206, 1361-1364.

SCHNEIDER, E. G., ROSTORFER, H. H., AND NASH, F. D. (1968). Distribution volume and metabolic clearance rate of renin in anesthetized nephrectomized dogs. Amer. J. Physiol. 215, 1115-1122.

Steel, R. G. D., AND Torrie, J. M. (1960). Principles and Procedures of Statistics. Pp. 67-86, 99-128. McGraw-Hill, New York.

TAPIA, M. M., Kuster, G. G. R., WoOds, J. E., AND STRONG, C. G. (1973). Renin activity in canine acute hepatic necrosis and chronic toxic hepatitis. Canad. J. Physiol. and Pharmacol. 51, 360-365.

ViCTERY, W., ThOMAS, D., SCHOEPS, P., AND VANDER, A. J. (1982a). Lead increases urinary zinc excretion in rats. Biol. Trace Element Res. 4, 211-219.

VICTERY, W.. VANDER, A. J., MaRkel, H., KatzMan, L., Shulak, J. M., AND Germain, C. (1982b). Lead exposure, begun in utero, decreases renin and angiotensin II in adult rats. Proc. Soc. Exp. Biol. Med. 170, 63-67.

WALLACE, K. B., BAILIE, M. D., AND HoOK, J. B. (1978). Angiotensin-converting enzyme in developing lung and kidney. Amer. J. Physiol. 234, R141-R145. 